\title{
Fitase na Alimentação da Tilápia do Nilo (Oreochromis niloticus). Desempenho e Digestibilidade
}

\author{
Wilson Massamitu Furuya1, Giovani Sampaio Gonçalves², Valéria Rossetto Barriviera Furuya ${ }^{3}$, \\ Carmino Hayashi ${ }^{3}$
}

\begin{abstract}
RESUMO - Este experimento foi realizado para avaliar os efeitos da adição de diferentes níveis de fitase $(0,500,1500$ e 3000 unidades de fitase ativa [UFA] $/ \mathrm{kg}$ de ração) em dietas para a tilápia do Nilo $(8,88 \pm 0,02 \mathrm{~g})$. Todas as rações foram fornecidas até saciedade durante 45 dias. O nível de fitase baseou-se nos parâmetros de desempenho e digestibilidade e foi estimado pelos modelos quadrático e/ou LRP (“broken line"). De acordo com os resultados obtidos com os níveis de fitase, o modelo LRP apresentou o melhor ajustamento de dados. A suplementação de fitase aumentou o desempenho, a retenção de minerais nos ossos, a digestibilidade da proteína e a disponibilidade de cálcio e fósforo. Os melhores resultados de desempenho, retenção de minerais nos ossos e digestibilidade foram obtidos com 700 UFA/kg de ração.
\end{abstract}

Palavras-chave: desempenho, digestibilidade, fitase, Oreochromis niloticus, tilápia do Nilo

\section{Phytase as Feeding for Nile Tilapia (Oreochromis niloticus). Performance and Digestibility}

ABSTRACT - This experiment was carried out to evaluate the effects of addition of different levels of phytase (0, 500, 1500 and 3000 units of active phytase [UFA] $/ \mathrm{kg}$ diet $)$ in the diets for Nile tilapia $(8.88 \pm 0.02 \mathrm{~g})$. All diets were fed to satiation daily for 45 days. The phytase level determination was based on the performance and digestibility parameters and was estimated by the quadratic and/ or the broken line models. The broken line model showed a better adjustment for phytase levels according to the observed results. Phytase supplementation increased performence, bone minerals, protein digestibility and calcium and phosphorus availability. The best results of performance, bone mineral retentions and digestibility were obtained with $700 \mathrm{UFA} / \mathrm{kg}$ of diet.

Key Words: digestibility, Oreochromis niloticus, performance, phytase, Nile tilapia

\section{Introdução}

A criação de peixes em tanques-rede ou "raceways" requer a utilização de rações completas, uma vez que, nesses sistemas, o alimento natural possui pequena participação na alimentação. As tilápias apresentam bons desempenhos nesses sistemas, além de possuir carne com boas características organolépticas e filé sem espinhos intramusculares em forma de "Y".

As rações formuladas com base em proteína da farinha de peixe possuem teor de fósforo $(\mathrm{P})$ acima das exigências estabelecidas pelo NATIONAL RESEARCH COUNCIL - NRC (1993), para as tilápias. No meio aquático, esse mineral pode levar a eutrofização excessiva e comprometer a qualidade da água (VAN DER PLOEG e BOYD, 1991; ENGLISH et al., 1993) e alterar as características organolépticas da carcaça (VAN DER PLOEG e TUCKER, 1994).
Os ingredientes de origem vegetal possuem cerca de $75 \%$ do seu P na forma de P fítico (POPMA e GREEN, 1990), que não pode ser utilizado, pois a mucosa intestinal dos peixes não secreta fitase (VIELMA et al., 1998). A redução no desempenho é atribuída aos menores coeficientes de digestibilidade da proteína e disponibilidade dos macrominerais (SPINELLI et al., 1983; GATLIN e PHILLIPS, 1989).

Para o bagre do canal (Ictalurus punctatus), JACKSON et al. (1996) avaliaram a inclusão de 0, $500,1000,2000$ e 4000 unidades de fitase ativa (UFA)/kg de ração. Os autores concluíram que a utilização de 500 UFA/kg foi suficiente para permitir adequado desempenho e deposição de $\mathrm{P}$ no ossos. Esse resultado também foi obtido por CAIN e GARLING (1995), em estudo realizado com alevinos (2 g) de truta arco-íris (Oncorhynchus mykiss) alimentados com rações formuladas com proteína do farelo de soja.

\footnotetext{
${ }^{1}$ Prof. M.Sc., Depto. de Zootecnia, Univ. Est. de Maringá-UEM, Av. Colombo, 5790, Maringá-PR, Brasil. E.mail: furuya@wnet.com.br 2 Aluno do curso de Graduação em Zootecnia, UEM, Maringá-PR.

3 Doutorado em Ecologia de Ambientes Aquáticos Continentais, Nupelia/PEA/UEM, Maringá-PR.
} 
Em trabalho realizado com o salmão do Atlântico (Salmo salar), com peso vivo inicial de $108 \mathrm{~g}$, alimentados com ração formulada com base na proteína do farelo de soja, STOREBAKKEN et al. (1998) observaram que a fitase (500 UFA/kg) aumentou a digestibilidade da proteína ( 85 para $88,2 \%$ ) e a disponibilidade do fósforo (29,7 para 48,8\%). Os autores ressaltaram as implicações da utilização de fitase sobre a menor descarga desses nutrientes nos tanques de criação. Valores superiores de inclusão de fitase foram encontrados por LANARI et al. (1998) e VIELMA et al. (1998), com a truta arco-íris. Esses autores observaram que 1000 e 1500 UFA/kg, respectivamente, foram suficientes para máximo ganho de peso, retenção de minerais na carcaça e disponibilidade dos macrominerais.

Poucas são as informações sobre a utilização da fitase em rações para peixes tropicais. A adição dessa enzima, em rações elaboradas com ingredientes de origem vegetal, pode permitir aumento na digestibilidade dos nutrientes e, conseqüentemente, melhorar o desempenho e reduzir a excreção de nitrogênio e fósforo ao meio ambiente.

O objetivo do presente trabalho foi avaliar os efeitos de diferentes níveis fitase, em rações formuladas com ingredientes de origem vegetal, sobre o desempenho e a digestibilidade de nutrientes pela tilápia do Nilo (Oreochromis niloticus).

\section{Material e Métodos}

O presente estudo foi realizado no Laboratório de Aquicultura, da Universidade Estadual de Maringá, no período de 23/9 a 06/11/99. Foram utilizados 120 alevinos de tilápia do Nilo (linhagem tailandesa) com peso vivo inicial médio de $8,88 \pm 0,02 \mathrm{~g}$, distribuídos em um delineamento em blocos ao acaso com quatro tratamentos e cinco repetições, considerando-se como bloco o tanque com quatro tanques-rede, sendo que cada bloco continha todos os tratamentos.

Cada tanque-rede $(200 \mathrm{~L})$ continha uma pedra porosa acoplada a um soprador central. Os tanques foram cobertos com tela sombrite $(70 \%)$, além de possuir $60 \%$ da sua lâmina d'água coberta com aguapé (Eichornia crassipes), para minimizar a produção primária.

Os ingredientes foram previamente moídos até diâmetro igual ou inferior a $0,7 \mathrm{~mm}$. Os peixes foram alimentados até saciedade aparente, três vezes ao dia, às 8,12 e 16 h. Foi utilizada ração referência formulada somente com ingredientes de origem ve- getal, tendo como base a proteína dos farelo de soja (Tabela 1).

Para adição da fitase aos tratamentos, após mistura dos ingredientes, a enzima foi dissolvida em água $\left(42^{\circ} \mathrm{C}\right)$ na proporção de $30 \%$ do peso seco das ração. Esta foi homogeneizada, peletizada em moinho de carne e desidratada em estufa de ventilação forçada a uma temperatura de $50^{\circ} \mathrm{C}$ durante 18 horas. Posteriormente, os grânulos foram desintegrados, selecionando-se partículas com diâmetros entre 3 e $6 \mathrm{~mm}$. Foi utilizada fitase (BASF - $5000 \mathrm{UFA} / \mathrm{g}$ ), incluída em níveis de $0,500,1500$ e 3000 unidades de fitase ativa (UFA)/kg de ração.

Para determinação da digestibilidade aparente de nutrientes, foi utilizado óxido de crômio como indicador inerte $(0,1 \%)$. Foram utilizados 80 animais com peso vivo de 45,22 $\pm 3,88 \mathrm{~g}$ distribuídos em duas gaiolas plásticas, com $35 \mathrm{~cm}$ de diâmetro e $70 \mathrm{~cm}$ de

Tabela 1 - Composição percentual da ração referência Table 1 - Percentual composition of reference diet

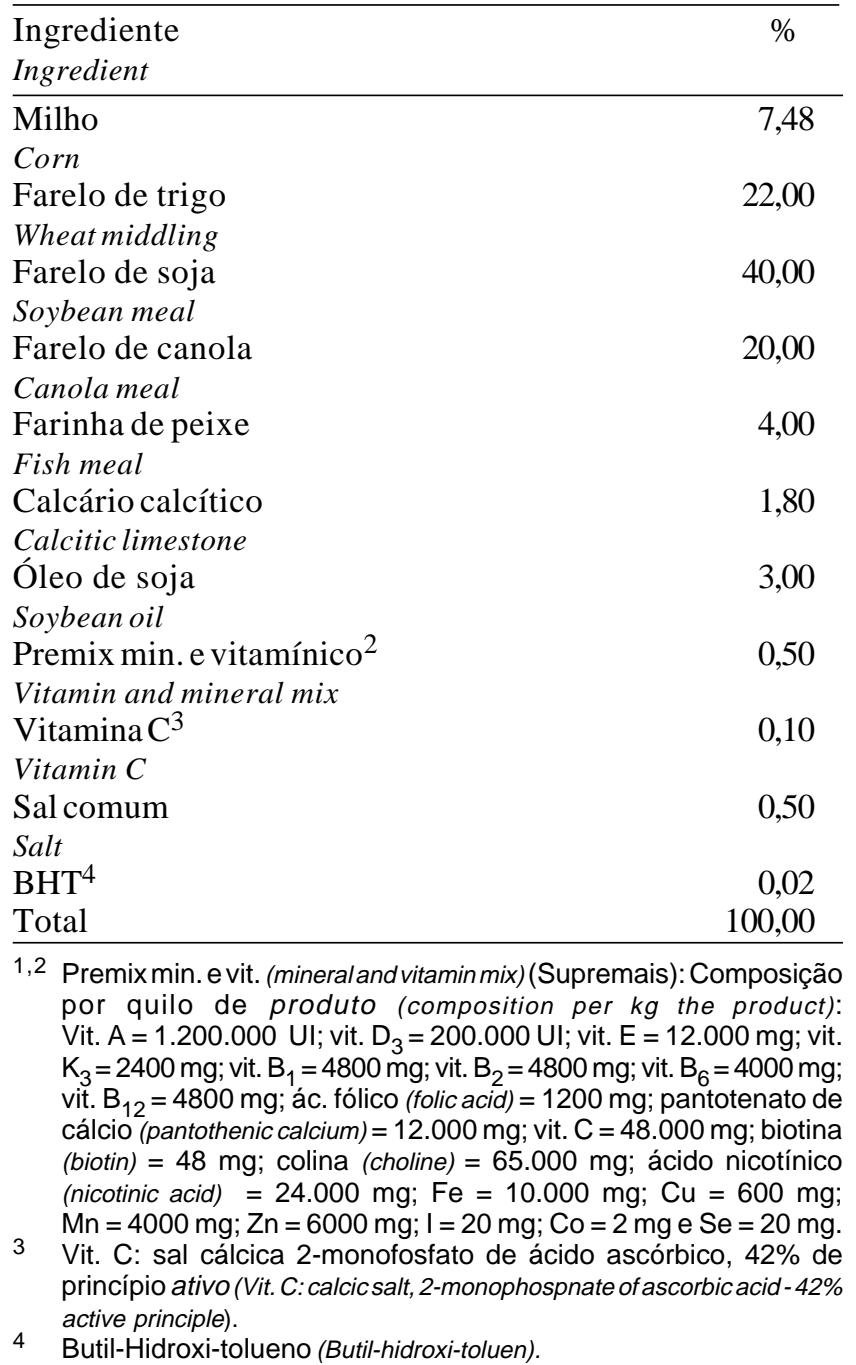


altura. As fezes foram coletadas pelo sistema de Guelph modificado por PEZZATO et al. (2001). A coleta de fezes, o preparo da amostra e a determinação da digestibilidade foram realizados de acordo as metodologias e expressões descritas por FURUYA et al. (1999). A temperatura e o oxigênio dissolvido da água dos aquários de digestibilidade e de alimentação foram mantidos por meio de aquecedores e pedra porosa acoplada a um aerador central, respectivamente.

Todos os animais foram pesados individualmente ao início e final do experimento em balança digital $(0,01 \mathrm{~g})$. Para a seleção dos peixes para distribuição nas unidades experimentais, procedeu-se à metodologia descrita por FURUYA et al. (1996).

Para análise de macrominerais, após pesagem, evisceração e determinação do rendimento de carcaça, dois peixes de cada unidade experimental foram mantidos em água aquecida $\left(80^{\circ} \mathrm{C}\right)$ durante dois minutos, retirando-se os ossos submandibulares com auxílio de pinça e, em seguida, lavagens com água destilada com auxílio de pincel e secagem em estufa $\left(105^{\circ} \mathrm{C}\right)$ durante 12 horas, sendo moídos em micromoinho para posterior análise de macrominerais.

A análise químico-bromatológica da ração referência foi realizada no Laboratório de Análise de Alimentos do Departamento de Zootecnia da Universidade Estadual de Maringá, enquanto as análises de óxido de crômio das rações e excretas e de cálcio, fósforo, zinco, ferro e magnésio dos ossos foram determinadas no Laboratório de Análise de Solos do Departamento de Agronomia da Universidade Estadual de Maringá. A análise químicobromatológica das rações, excretas e macrominerais dos ossos foram realizadas de acordo com a metodologia descrita por SILVA (1990), enquanto a de óxido de crômio seguiu a metodologia descrita por GRANER (1972).

Os parâmetros de oxigênio dissolvido $(\mathrm{mg} / \mathrm{L})$, condutividade elétrica $(\mu \mathrm{S} / \mathrm{cm})$ e $\mathrm{pH}$ da água de cada unidade experimental foram tomados a cada cinco dias. A temperatura da água foi aferida diariamente $(8$ e $18 \mathrm{~h}$ ). Essas medidas foram determinadas por "kit" digital portátil.

Foi utilizado o delineamento inteiramente casualizado, com cinco tratamentos e quatro repetições, sendo considerado como bloco o tanque-rede com os quatro tratamentos e, como unidade experimental, um tanque-rede com cinco peixes. As análises estatísticas das variáveis foram realizadas por análises de variância e de regressão polinomial ou LRP - Linear Response Plateau (Broken line), atra- vés do programa SAEG - Sistema de Análises Estatísticas e Genéticas (UNIVERSIDADE FEDERAL DE VIÇOSA, 1982). Os valores das expressos em porcentagem foram transformados pela expressão $\mathrm{y}=\operatorname{arcsen}$, sendo $\mathrm{x}$ o valor da variável em porcentagem.

\section{Resultados e Discussão}

Foram obtidos valores médios de $26,76 \pm 0,12^{\circ} \mathrm{C}$; $4,55 \pm 0,89 \mathrm{mg} / \mathrm{L} ; 7,25 \pm 1,12$ e $45 \pm 2,68 \mu \mathrm{Sm} / \mathrm{cm}$, para temperatura, oxigênio dissolvido, $\mathrm{pH}$ e condutividade da água dos tanques, respectivamente, dentro da faixa recomendada por POPMA e GREEN (1990) para as tilápias.

A relação proteína:energia da ração referência (Tabela 2), de 92,27 (mg/kcal), encontra-se próxima do valor recomendado para as tilápias pelo NATIONAL RESEARCH COUNCIL - NRC (1993), assim como as porcentagens de cálcio, fibra bruta e extrato etéreo.

Na Tabela 3 encontram-se os valores médios de desempenho produtivo e de macrominerais nos ossos da tilápia do Nilo, em função dos níveis de fitase (unidade de fitas ativa - UFA)/kg de ração.

Tabela 2 - Composição química ração referência (base na matéria natural)

Table 2 - Chemical composition of reference diet (as fed basis)

\begin{tabular}{|c|c|c|}
\hline & $\begin{array}{c}\text { Unidade } \\
\text { Unit }\end{array}$ & $\begin{array}{l}\text { Valor } \\
\text { Value }\end{array}$ \\
\hline Matéria seca ${ }^{1}$ & $\%$ & 93,09 \\
\hline $\begin{array}{l}\text { Dry matter } \\
\text { Energia digestível }\end{array}$ & $\mathrm{kcal} / \mathrm{kg}$ & 3131,83 \\
\hline $\begin{array}{l}\text { Digestible energy } \\
\text { Proteína digestível }^{2} \\
\text { Digestible protein }\end{array}$ & $\%$ & 28,90 \\
\hline $\begin{array}{l}\text { Fibra bruta }{ }^{1} \\
\text { Crude fiber }\end{array}$ & $\%$ & 6,44 \\
\hline $\begin{array}{l}\text { Extrato etéreo } \\
\text { Ether extract }\end{array}$ & $\%$ & 4,88 \\
\hline $\begin{array}{l}\text { Cálcio }^{1} \\
\text { Calcium }\end{array}$ & $\%$ & 1,34 \\
\hline $\begin{array}{l}\text { Fósforo total } \\
\text { Total phosphorus }\end{array}$ & $\%$ & 0,72 \\
\hline $\begin{array}{l}\text { Fósforo disponível } \\
\text { Available phosphorus }\end{array}$ & $\%$ & 0,26 \\
\hline
\end{tabular}

1 Análise realizada no Laboratório de Análise de Alimentos do Departamento de Zootecnia da Universidade Estadual de Maringá - UEM, Maringá-PR (Analysis were determined at Animal Nutrition Lab of Animal Science Department of State University of Maringá, Maringá-PR).

2 Valores segundo PEZZATO et al. (2001) (Values according to PEZZATO et al. [2001]).

3 Valores segundo LEESON (1999) (Values according to LEESON [1999]). 
FURUYA et al.

Tabela 3 - Valores médios de desempenho da tilápia do Nilo alimentada com rações com níveis crescentes de fitase Table 3 - Mean values of performance of Nile tilapia fed rations with increasing levels of phytase

\begin{tabular}{|c|c|c|c|c|c|}
\hline \multirow[t]{2}{*}{$\begin{array}{l}\text { Variável } \\
\text { Variable }\end{array}$} & \multicolumn{5}{|c|}{$\begin{array}{c}\text { Fitase (UFA/kg de dieta) } \\
\text { Phytase }\end{array}$} \\
\hline & 0 & 500 & 1500 & 3000 & $\mathrm{CV}$ \\
\hline $\begin{array}{l}\text { Peso inicial }(\mathrm{g}) \\
\text { Inicial weight }\end{array}$ & 8,88 & 8,87 & 8,87 & 8,84 & 2,36 \\
\hline $\begin{array}{l}\text { Peso final }(\mathrm{g}) \\
\text { Final weight }\end{array}$ & 34,28 & 39,39 & 41,29 & 42,99 & 9,26 \\
\hline $\begin{array}{l}\text { Ganho de peso }(\mathrm{g})^{1} \\
\text { Weight gain }\end{array}$ & 24,75 & 24,28 & 31,33 & 32,56 & 9,24 \\
\hline $\begin{array}{l}\text { Conversão alimentar } \\
\text { Feed:gain ratio }\end{array}$ & 1,97 & 1,80 & 1,61 & 1,33 & 16,44 \\
\hline $\begin{array}{l}\text { Sobrevivência }(\%) \\
\text { Survival }\end{array}$ & 96,67 & 100,00 & 93,33 & 97,67 & 7,21 \\
\hline $\begin{array}{l}\text { Rendimento de carcaça }(\%)^{2} \\
\text { Carcass yield } \\
\text { Mineral nos osso }(\%) \\
\text { Mineral in bone } \\
\text { Cálcio }(\%)^{2}\end{array}$ & 80,62 & 80,92 & 81,50 & 82,77 & 0,63 \\
\hline $\begin{array}{l}\text { Calcium } \\
\text { Fósforo }(\%)^{2}\end{array}$ & 17,78 & 19,17 & 22,20 & 22,98 & 11,13 \\
\hline $\begin{array}{l}\text { Phosphorus } \\
\text { Zinco }(\%)\end{array}$ & 5,35 & 5,69 & 5,69 & 3,20 & 5,53 \\
\hline $\begin{array}{l}\text { Zinc } \\
\text { Magnésio }(\%)^{2}\end{array}$ & 0,01 & 0,01 & 0,02 & 0,02 & 0,01 \\
\hline $\begin{array}{l}\text { Magnesium } \\
\text { Ferro }(\%)\end{array}$ & 0,18 & 0,21 & 0,19 & 0,23 & 0,01 \\
\hline Iron & 0,05 & 0,05 & 0,06 & 0,06 & 0,01 \\
\hline
\end{tabular}

Não foi observado efeito $(\mathrm{P}>0,05)$ dos níveis de inclusão de fitase nas rações sobre as variáveis de sobrevivência e retenção de zinco e ferro nos ossos. Este resultado evidencia que o nível de fósforo na ração referência sem a suplementação de enzima atendeu as exigências de mantença, o que também foi observado por JACKSON et al. (1996), em trabalho realizado com o bagre do canal, utilizando ração referência formulada com base em ingredientes de origem vegetal.

Pelo modelo LRP (Linear Response Plateau), o ganho de peso aumentou $(\mathrm{P}<0,05)$ até o valor de 890 UFA/kg. O nível de fitase estimado para o ganho de peso foi superior ao encontrado por JACKSON et al. (1996), para o bagre do canal, de 500 UFA/kg, e inferior aos encontrados por LANARI et al. (1998) e VIELMA et al. (1998), de 10001500 UFA/kg, para a truta arco-íris.

A conversão alimentar melhorou $(\mathrm{P}<0,05)$ linearmente com o aumentos nos níveis de fitase. Também foram observados aumentos $(\mathrm{P}<0,05)$ lineares no rendimento de carcaça e na retenção de cálcio, fósforo e magnésio nos ossos (Tabela 3). Os efeitos positivos da adição de fitase sobre a retenção de macrominerais também foram observados por GATILIN e PHILLIPS (1989), em estudo realizado com o bagre do canal, e por CAIN e GARLING (1995) e VIELMA et al. (1998), em trabalho realizado com a truta arco-íris.

O aumento no ganho de peso, no rendimento de carcaça e na retenção de minerais nos ossos e a melhora na conversão alimentar estão relacionados com os efeitos positivos da fitase sobre a digestibilidade da proteína e disponibilidade dos minerais (cálcioe fósforo) (Tabela4).

Pelo modelo LRP, não foi observado aumento na digestibilidade da proteína a partir de 463 UFA/kg de ração. Por outro lado, a máxima disponibilidade do cálcio e fósforo foi estimada com a inclusão de 702 e 688 UFA/kg de ração, respectivamente. 
928 Rev. bras. zootec.

Tabela 4 - Valores médios de digestibilidade da proteína e disponibilidade do cálcio e fósforo pela tilápia do Nilo, alimentada com rações com níveis crescentes de fitase

Table 4 - Means values of protein digestibility and calcium and phosphorus availability of Nile tilapia fed rations with increasing levels of phytase

\begin{tabular}{|c|c|c|c|c|c|}
\hline \multirow[b]{2}{*}{$\begin{array}{l}\text { Digestibilidade aparente }(\%) \\
\text { Apparent digestibility }\end{array}$} & \multicolumn{4}{|c|}{$\begin{array}{c}\text { Fitase (UFA/kg) } \\
\text { Phytase }\end{array}$} & \multirow[b]{2}{*}{$\mathrm{CV}$} \\
\hline & 0 & 500 & 1500 & 3000 & \\
\hline Proteína bruta $(\%)^{*}$ & & & & & \\
\hline $\begin{array}{l}\text { Crude protein } \\
\text { Cálcio }(\%)^{*}\end{array}$ & 89,59 & 92,95 & 93,12 & 92,68 & 1,45 \\
\hline $\begin{array}{l}\text { Calcium } \\
\text { Fósforo }(\%)^{*}\end{array}$ & 34,32 & 48,55 & 54,17 & 55,17 & 7,52 \\
\hline Phosphorus & 38,21 & 65,23 & 72,63 & 78,19 & 4,91 \\
\hline
\end{tabular}

No presente estudo, com 500 UFA/kg, a digestibilidade da proteína aumentou de 88,83 para 92,59\%, aproximando-se do valor citado por STOREBAKKEN et al. (1998), que observaram acréscimo na digestibilidade da proteína de 85 para $88,2 \%$, com esse mesmo valor de inclusão de fitase, confirmando as citações de SPINELLI et al. (1983) sobre a ação dessa enzima sobre o rompimento do complexo fitato-proteína.

A disponibilidade do cálcio e fósforo assemelhou-se aos dos obtidos por LANARI et al. (1998) e VIELMA et al. (1998), em estudos realizados com truta arcoíris alimentada com rações formuladas com base na proteína do farelo de soja.

Os resultados dos presente trabalho confirmam os de GATLIN e PHILLIPS (1989), em que se constatou a ação negativa do fósforo fítico sobre a digestibilidade de nutrientes. A fitase aumentou a digestibilidade da proteína e a disponibilidade dos minerais, favorecendo o desempenho e diminuindo a descarga de nutrientes para o meio aquático, reduzindo a possibilidade de eutrofização, que pode comprometer a qualidade da água (VAN DE PLOEG e BOYD, 1991), o desempenho (ENGLISH et al., 1993) e as características organolépticas da carcaça (VAN DE PLOEG e TUCKER, 1994).

\section{Conclusões}

A utilização de ração com 700 unidades de fitase ativa (UFA)/kg é adequada para o desempenho produtivo, a digestibilidade da proteína e disponibilidade do cálcio e fósforo da tilápia do Nilo, na fase inicial, alimentada com ração formulada com ingredientes de origem vegetal, tendo como base a proteína do farelo de soja.

\section{Referências Bibliográficas}

CAIN, K., GARLING, D.L. 1995. Pretreatment of soybean meal with phytase for salmonid diets to reduce phosphorus concentrations in hatchery effuents. The Progressive Fish Culturist, 57(2):114-119.

ENGLISH, W.R., SCHWEDLER, T.E., DYCK, L.A. 1993. Aphanizomenon flos-aquae, a toxic blue green alga in commercial channel catfish, Ictalurus punctatus, ponds: a case history. J. Appl. Aquacult., 3:195-209.

FURUYA, W.M., HAYASHI, C., FURUYA, V.R.B. et al. 1996 Exigência de proteína para machos revertidos de tilápia do Nilo (Oreochromis niloticus L.), na fase juvenil. Rev. UNIMAR, 18(2):307-319.

FURUYA, W.M., PEZZATO, L.E., FURUYA, V.R.B. et al. Digestibilidade aparente da proteína e aminoácidos do farelo de canola pela tilápia do Nilo, Oreochromis niloticus. In: CONGRESSO SUR AMERICANO DE ACUICULTURA, 2, 1999, Puerto La Cruz. Memorias... Puerto La Cruz: WAS/ASA/SVA, 1999. p.206-217.

GATLIN, D.M., PHILLIPS, H.F. 1989. Dietary calcium, phytate and zinc interactions in channel catfish. Aquaculture, 79:259-266.

GRANER, C.A.F. Determinação do crômio pelo método colorimétrico da s-difenilcarbazida. Botucatu, SP, 1972. 112p. Tese (Doutorado em Ciências) - Faculdade de Ciências Médicas e Biológicas, Universidade Estadual Paulista, 1972.

JACKSON, L.S., LI, M.H., ROBINSON, E.H. 1996. Use of microbial phytase in channel catfish Ictalurus punctatus diets to improve utilization phytate phosphorus. J. World Aquacult. Soc., 27(3):309-313.

LANARI, D., D'AGARO, E., TURRI, C. 1998. Use of nonlinear regression to evaluate the effects of phytase enzime treatment of plant protein diets rof rainbow trout (Oncorhynchus mykiss). Aquaculture, 161:345-356.

LEESON, S. Enzimas para aves. In: SIMPÓSIO INTERNACIONAL SOBRE NUTRIÇÃO DE AVES, 1999, Campinas. Anais.... Campinas: FACTA, 1999. p.173-185. 
NATIONAL RESEARCH COUNCIL - NRC. 1993. Nutrient Requirements of warmwater fishes na shellfishes. Washington: National Academy Press. 102p.

PEZZATO, L.E., MIRANDA, E.C., PEZZATO, A.C. et al. 2001. Digestibilidade aparente de ingredientes pela tilápia do Nilo (Oreochromis niloticus). Rev. bras. zootec. (no prelo).

POPMA, T.J., GREEN, B.W. 1990. Sex reversal of tilapia in earthen ponds. Aquaculture production manual. Alabama: Auburn University, Alabama Research and Development. Series $35.15 \mathrm{p}$.

ROBINSON, E.H., JACKSON, S., LI, M.H. 1996. Aquaculture Magazine, 3(12):1-8.

SILVA, S.S. 1990. Análise de alimentos (métodos químicos e biológicos). 2.ed., Viçosa: UFV. 166p.

SPINELLI, J., HOULE, C.R., WEKELL, J.C. 1983. The effect of phytate on the growth of rainbow trout (Salmo gairdneri) fed purified diets containing varying quanties of calcium and magnesium. Aquaculture, 30:71-83.

STOREBAKKEN, K.D., SHEARER, K.D., ROEM, A.J. 1998. Availability of protein, phosphorus and other elements in fish meal, soy protein concentrate and phytase treated soy protein based diets to Atlantic salmon, Salmo salar. Aquaculture, 161(1-4):365-379.
UNIVERSIDADE FEDERAL DE VIÇOSA - UFV. 1982. Centra de Processamento de Dados - UFV - CPD. SAEG - Sistema para análise estatística e genética. Viçosa: UFV. 59p.

VAN DER PLOEG, M., BOYD, C.E. 1991. Geosmin production by cyanobacteria (blue green algae) in fish ponds at Auburn, Alabama. J. World Aquacult. Soci., 22:207-216.

VAN DER PLOEG, M., TUCKER, C.S. 1994. Seasonal trends in flavor quality of channel catfish, Ictalurus punctatus, from commercial ponds in Mississippi. J. Appl. Aquac., 3:121-140.

VIELMA, J., LALL, S.P., KOSKELA, J. et al. 1998. Effects of dietary phytase and cholecalciferol on phosphorus bioavailability in rainbow trout (Oncorhynchus mykiss). Aquaculture, 63(3/4):309-323.

Recebido em: 06/10/00

Aceito em: 19/03/01 